\title{
ТАКСОНОМИЯ МЕТАФОРИЧЕСКИХ ЕДИНИЦ И ВЫДЕЛЕНИЕ СМЕШАННОЙ МЕТАФОРЫ В АНГЛИЙСКОМ ЯЗЫКЕ
}

\section{THE TAXONOMY OF METAPHORICAL ITEMS AND THE ALLOCATION OF MIXED METAPHOR IN ENGLISH}

M. Taymour

Summary: This article is devoted to the problem of mixed metaphor among other metaphorical units in the English language and the allocation of mixed metaphor in the general system of metaphoric language as a separate linguistic phenomenon. The role of mixed metaphor in modern linguistics is examined and the taxonomy of the propositional structure of the metaphor is studied. To analyse the components of mixed metaphor, the theory of rhetorical structure is used and a procedure for the analysis of a metaphorical unit is developed in order to discriminate a mixed metaphor.

Key words: mixed metaphor; taxonomy; source domain; conceptual scheme; metaphorical unit.

\author{
Таймур Мария Павловна \\ Аспирант-соискатель, преподаватель, Московский \\ государственный лингвистический университет \\ mariataymour@gmail.com
}

Аннотация: Данная статья посвящена проблеме смешанной метафоры в ряду других метафорических единиц в английском языке и ее выделения в общей системе метафорического языка как отдельно стоящего лингвистического феномена. В работе рассматривается роль смешанной метафоры в современной лингвистике и производится рассмотрение таксономии пропозициональной структуры метафоры. Для анализа составляющих смешанную метафору частей используется теория риторической структуры и разрабатывается процедура анализа метафорической единицы для выделения смешанной метафоры.

Ключевые слова: смешанная метафора; таксономия; домен-источник; концептуальная схема; метафорическая единица.

Добровольский [1997] определяет намеренность (intentionality) как основной параметр вариации идиом, выделяя на этом основании 3 основных класса: систематическая вариация, игра слов (каламбур) и ошибочные варианты. В то время, как предлагается исключать последние, определяемые как контаминации (или СМ в нашей терминологии), из анализа регулярной вариативности [Langlotz 2006: 201], отмечается, что многие подобные идиоматические выражения уже зафиксированы в словарях (напр., малафора The dust clears = the dust settles $и$ the fog clears засвидетельствована словарем Collins Cobuild Dictionary of Idioms), что позволяет интерпретировать их как единицы языка, получившие статус стандартных вариантов. Кроме того, само понятие намеренности имеет субъективную природу, и "to be able to characterise a given activity as intentional, it must be first interpreted as being intentional by the perceiver" (чтобы иметь возможность охарактеризовать данное действие как намеренное, оно должно сначала восприниматься адресатом как намеренное) [ibid: 203]. Это говорит о том, что границы между различными классами вариаций идиом нестабильны и открыты для различных интерпретаций. Помимо этого, "one cannot expect a uniform variation potential for different idioms in different context-specific usage-events" (нельзя ожидать единого потенциала вариации для разных идиом в разных контекстно-зависимых событиях) [ibid: 225], то есть можно утверждать, что лексикограмматическое поведение идиоматических выражений (в т.ч. СМ и прочих окказионализмов) определяется одновременным действием 
двух противоположных сил - изменчивости и стабильности их формы. А новое выражение, возникшее в результате смешения более конвенциональных языковых единиц, должно быть коммуникативно функциональным, чтобы реципиент имел возможность декодировать его, опираясь на контекст и собственные фоновые знания. Причем, "the speaker's attempt to maximise the relevance of the variant amounts to a communicative tightrope-walk that is subjected to a number of limitations" (попытка говорящего максимизировать актуальность данного варианта напоминает коммуникативную прогулку по канату с рядом ограничений) [ibid: 214], и, если подобная результирующая малафора не воспринимается адресатом как идиоматическое выражение, она перестает быть идиомой и теряет смысл. Т.е. только в СМ, созданных преднамеренно, можно адаптировать лексико-грамматическую структуру так, чтобы она была функциональной, грамматически обоснованной и совместимой с идиоматическим значением.

Известно, что СМ отличается «разнообразием форм, когнитивных предпосылок их создания, модальностей и уровня когнитивного диссонанса, возникающего у реципиента при их восприятии» [Таймур 2020: 176], и целью данной работы является рассмотрение таксономии пропозициональной структуры метафоры (a taxonomy of the propositional structure of metaphors) для определения места СМ в системе метафорического языка. П. Крисп, Дж. Хейвуд и Дж. Стейн предлагают следующую систему оппозиций метафор: single (единичная) vs multiple (множественная) метафора, simple (простая) vs complex (сложная) метафора, pure (чистая) vs mixed (смешанная) метафора, restricted (узкая) vs extended (расширенная) метафора [Crisp, Heywood \& Steen 2002, с. 55]. Для анализа системы оппозиций рассмотрим различия в использовании метафорических выражений в следующих предложениях:

1. This learner always absorbs everything a teacher says.

2. The teacher has already set her mark on that learner.

3. She sometimes has a sudden rush of nostalgia.

4. The performance was the stuff of melodrama.

В первом предложении лишь одно слово использовано метафорически (absorbs), в то время как в остальных предложениях по два слова. Более того, в предложениях 2 и 3 оба слова принадлежат к одному домену-источнику (source domain), в то время как в предложении 4 - к различным. Разница между предложениями 2 и 3, однако, также присутствует - в предложении 2 оба метафорически использованных слова являются двумя элементами одной метафоры (предикативный концепт set и главный концепт mark), а вот в предложении 3 оба слова sudden rush являются частями единого концепта метафорического выражения. Это приводит к выводу, что для разработки таксономии метафорических выражений должны быть рассмотрены их аналитические уровни (analytic levels of the surface linguistic expression), пропозиция, или суждение (proposition) и составлена концептуальная схема (conceptual mapping) [Crisp, Heywood, Steen 2002]. Очевидно, что метафорические выражения в дискурсе не всегда бывают так четко обозначены, как в предложенных выше примерах. Для анализа более сложных структур и составляющих их частей мы воспользуемся теорией риторической структуры (Rhetorical Structure Theory), где вводится понятие non-downgraded clause, и разделяются понятия «предложение» и «единица текста» (text unit or T-unit) [Mann, Thompson 1998, c. 243]. T-unit представляется нам весьма удобным понятием для задач настоящего исследования, постольку этим термином обознаются части текста, образующие семантические целостные конструкции, представляя идеи текста как интегрированные, но в то же время обособленные единицы, и являясь поверхностной лингвистической единицей дискурса, что крайне важно для структурного анализа именно смешанных метафор. Например, в двух предложениях, позаимствованных у С. Майтланд [Maitland 1990], определим количество имеющихся T-units:

5. Only in her anger could she drown out the dark shadow that pity and guilt cast over her.

6. She grew moody and inward and sat behind her dustlines, besieged within her own fortifications.

Несмотря на то, что в предложении 5 присутствуют несколько метафорических выражений, все предложение может считаться одним Т-юнитом, в то время как в предложении 6 содержит три T-units. В предложении 5 придаточное предложение присоединяется к главному предложению структурой the dark shadow that, которая не обладает семантической независимостью, необходимого условия для обозначения eе T-unit. А вот предложение 6 может быть разложено на несколько семантически независимых T-units: a) She grew moody and inward; b) and sat behind her dustlines; c) besieged within her own fortifications. Схематическое представление таксономии метафорических выражений может быть представлено следующим образом (см. Рис.1), где две комбинации из 16 являются логически невозможными, поскольку невозможно получить смешанную метафору при комбинировании единичной и простой метафоры (независимо от того, узкая она или расширенная).

Таким образом, анализ метафорической единицы для выделения смешанной метафоры может быть построен по следующему алгоритму:

1. определяется степень расширенности метафоры (где каждый T-unit, содержащий одно или более метафорически употребленных слов, может быть либо ограниченным, где метафора не продолжается в другом Т-юните (restricted), либо распространенным (extended));

2. определяется количество имеющихся в каждом метафорическом выражении (или Т-юните) метафорических семантических единиц, (соответственно подразделяя T-unit на multiple или singular). Да- 


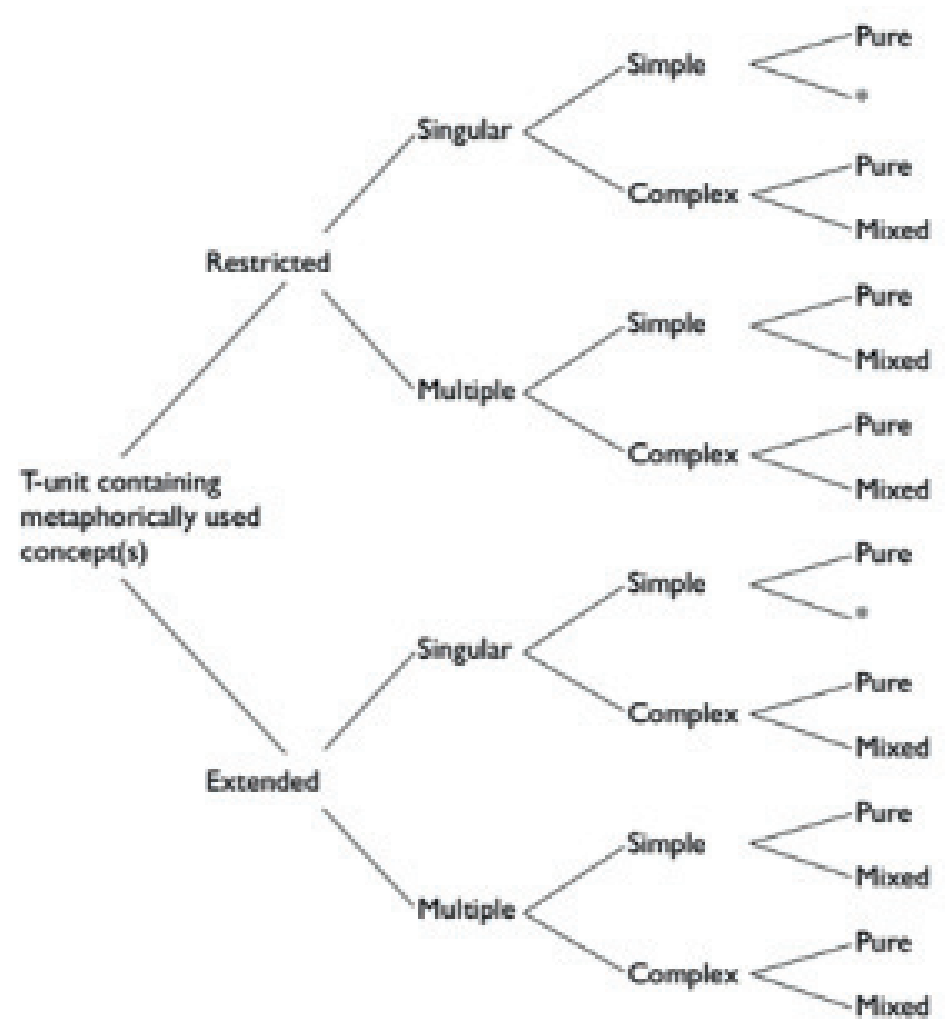

Рисунок 1. Таксономия метафорических выражений (Crisp, Heywood \& Steen 2002: 64)

лее в зависимости от этого:

3. определяется наличие в метафорическом выражении подструктур, содержащих еще хотя бы одну метафорическую семантическую единицу (подразделение на complex и simple);

4. если результат 2 и/или 3 шага положителен, определяется, является ли метафорическая единица pure metaphor (чистой метафорой) vs mixed metaphor (смешанной метафорой).

Кроме того, функциональность ограничивает намеренную адаптацию идиомы для достижения конкретной коммуникативной цели в данной коммуникативной ситу- ации, и это ограничение приводит к качественному различию между неумышленными, нефункциональными, т.е. неудачными СМ и идиоматической игрой слов, которая всегда должна быть функциональной по определению. То есть, можно быть вполне уверенным в том, что "the functionality criterion is dependent on considerable overlap between the speaker's and hearer's cognitive environments" (критерий функциональности зависит от значительного совпадения когнитивной среды говорящего и слушателя) [Langlotz 2006: 220], а данный подход может быть использован для идентификации СМ и ее подвидов в различных типах дискурса, что представляет несомненный интерес для дальнейших исследований.

ЛИТЕРАТУРА

1. Голубкова Е.Е., Таймур М.П. Факторы преодоления когнитивного диссонанса в смешанных метафорах (на материале английского языка). Когнитивные исследования языка. 2019. №36. С. 147-154.

2. Таймур М.П. Когнитивный диссонанс в смешанных метафорах на английском языке // Вестник Московского государственного лингвистического университета. Гуманитарные науки. 2019. Выпуск № 829. С. 84-95.

3. Таймур М.П. Классификация смешанных метафор: когнитивные предпосылки // Современная наука: актуальные проблемы теории и практики. Гуманитарные науки. 2020. №2. С. 176-178.

4. Crisp P., Heywood J., Steen J. Metaphor identification and analysis, classification and quantification // Language and Literature, Vol 11(1), 2002. UK: SAGE Publications. P. 55-69.

5. Dobrovol'skji D. Idiome im mentalen Lexikon: Ziele und Methoden der kognitiv- basierten Phraseologieforschung. Trier: Wissenschaftlicher Verlag Trier, 1997. 
6. Kimmel, M. Why We Mix Metaphors (and Mix Them Well) // Journal of Pragmatics, 42. University of Vienna, 2009. P. 97-115.

7. Langlotz A. Idiomatic creativity. Amsterdam / Philadelphia: John Benjamin Publishing Company, 2006. $340 \mathrm{p}$.

8. Maitland S. Three Times Table. UK: London, Chatto and Windus, 1990. 233 p.

9. Mann W., Thompson S. Rhetorical Structure Theory: Toward a functional theory of text organization // Interdisciplinary Journal for the study of Discourse, 8(3). USA: University of California, 1998. P.243-281.

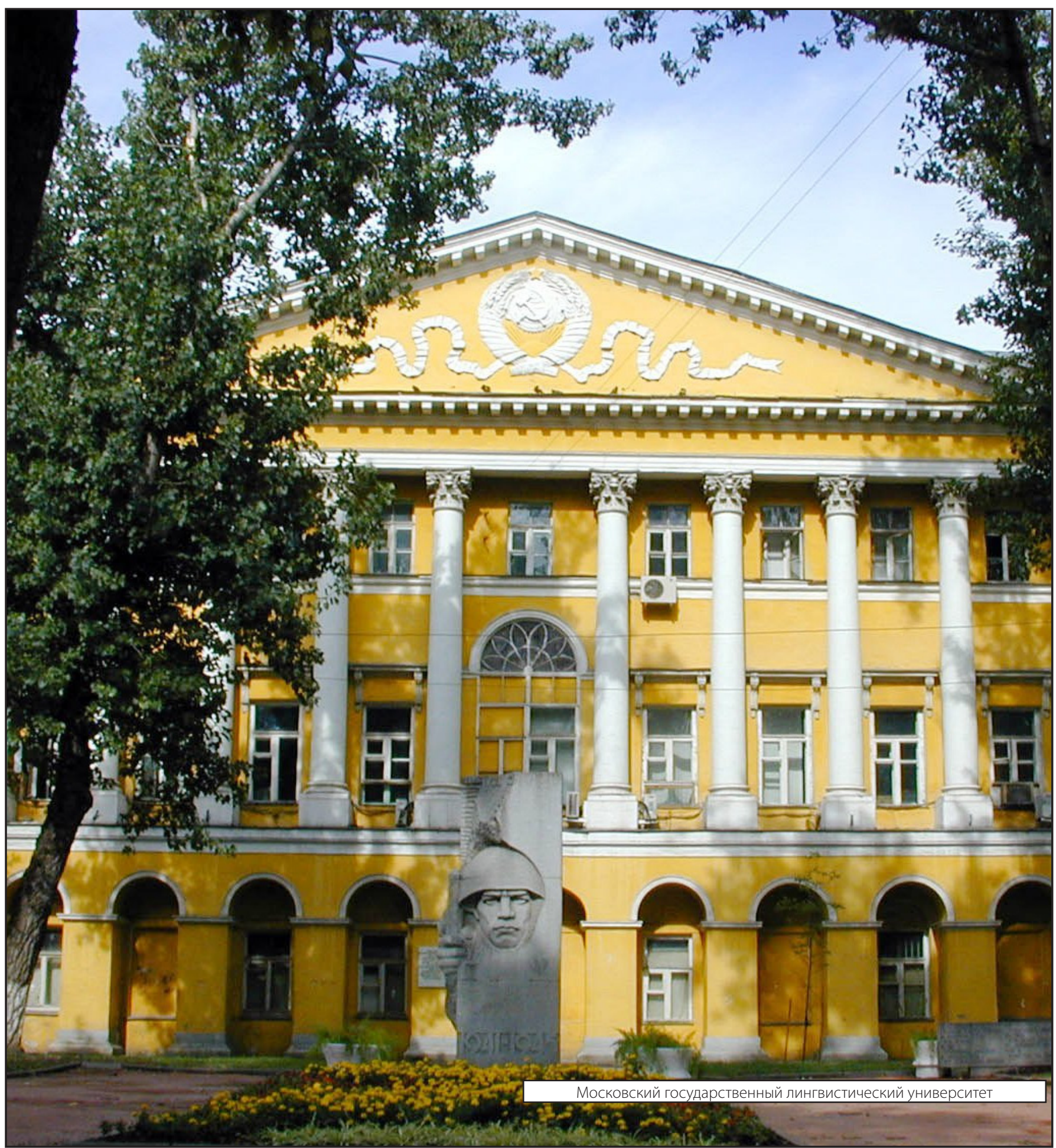

